NECROLOGÍA

\title{
Homenaje a Frédéric Siordet
}

El señor Frédéric Siordet, ex miembro del CICR y ex vicepresidente de la Institución, falleció el 30 de enero de 1991. Con su muerte desaparece una de las grandes figuras del Comité Internacional de la Cruz Roja.

$\mathrm{Su}$ amigo Melchior Borsinger, ex delegado general del CICR para Europa y América del Norte, galardonado con la medalla Henry Dunant, rinde homenaje, en las líneas que siguen, a este gran servidor de la Cruz Roja. En ellas sabe expresar los sentimientos de admiración y de afecto que comparten hoy todos los que, en el CICR o en el Movimiento Internacional de la Cruz Roja y de la Media Luna Roja, reconocieron y apreciaron la gran competencia y las cualidades de corazón y de espíritu de Frédéric Siordet.

Frédéric Siordet, miembro del CICR de 1951 a 1979, y vicepresidente de la Institución en varias ocasiones durante ese período, se fue el 30 de enero de 1991, dejando un inmenso vacío.

Era un hombre de gran modestia e increíblemente dotado en ámbitos muy diversos. Hijo de pastor y jurista de formación, fue, por sus antecedentes, tanto un hombre del espíritu como de la razón. Brillante humanista, melómano apasionado, manejaba una pluma alerta y precisa, unía un sentido del humor "anglosajón" a un gran ingenio innegablemente latino.

Durante muchos años, ejerció la abogacía en París y fue consejero jurídico de la Legación de Suiza. Cuando ésta tuvo que replegarse, en 1940, primero en Burdeos y después en Vichy, Frédéric Siordet dirigió las restringidas actividades de la Legación en París y ejerció funciones paraconsulares durante la ocupación alemana. 
Cuando, en 1943, se retiró de París para que sus hijas pudieran proseguir sus estudios en Suiza, Frédéric Siordet fue nombrado asesor del CICR y pronto entablamos lazos de amistad.

Fue un colega excelente, cortés y sensible. Bajo una gran modestia, albergaba un profundo conocimiento del hombre, de sus defectos, de sus vicios y de sus virtudes. Su humor, su bondad y sus travesuras fueron, para los que lo conocieron y trabajaron con él, un gran apoyo en una época difícil y sombría para toda la humanidad.

Terminada la guerra, fue llamado para participar en los trabajos preparatorios encaminados a reelaborar los Convenios de Ginebra existentes y, especialmente, a redactar el nuevo IV Convenio de Ginebra para proteger a la población civil en tiempo de guerra. Su experiencia de la guerra y de la ocupación en París fue de gran utilidad en esta tarea.

A partir de 1950, con Jean Pictet, Claude Pilloud, René-Jean Wilhelm y Jean de Preux, fue uno de los que más contribuyó a redactar el Comentario de esos Convenios. A1 margen de su trabajo, su humor nos alegró a menudo, cuando redactó, por ejemplo, un «Resumen de los Convenios con la letra p». El autor de estas líneas también recuerda, en particular, unos maravillosos «Plañidos para Pilloud», cuyo comienzo, si la memoria no me falla, era: «Pauvre petit Pilloud, précairement penché pupitre périlleux profondément perplexé par problèmes propagation principes protection prisonniers pugnaces, pleure pour prononcer paroles propices!» (¡Pobre pequeño Pilloud, precariamente pandeado pupitre peligroso profundamente perplejo por problemas propagación principios protección prisioneros pugnaces, plañe por pronunciar palabras propicias!).

Frédéric Siordet representó, además, al CICR en numerosos países, así como en varias conferencias de la Cruz Roja, y escribió Inter Arma Caritas, notable obra de reflexión sobre las actividades del CICR durante la II Guerra Mundial.

Pero, Frédéric Siordet no era solamente, ni mucho menos, un hombre de pluma y escritorio, fue también un hombre de acción. Efectuó para el CICR numerosas e importantes misiones, entre las que cabe destacar una vuelta al mundo en 1945 y 1946, durante la cual visitó todas las Sociedades Nacionales de la Cruz Roja de Asia, de Australasia y de América central y del Norte, en unas condiciones que no son difíciles de imaginar, apenas terminada la guerra.

Otra misión lo llevó, durante el invierno de 1957, de la India al Sudeste asiático, a China, la URSS y Polonia, con el fin de exponer a los dirigentes de esos Estados la posición del CICR en relación con el problema, muy delicado entonces, de China y Taiwán. Efectivamente, 
el hecho de que fuera la China del Kuomintang (Chang-Kai-Shek) la que firmó los Convenios de Ginebra en 1949 y la República Popular de China (Mao-Tse-Tung) la que los ratificó, comprometió seriamente la XIX Conferencia Internacional de la Cruz Roja en Nueva Delhi. Así pues, esta misión fue más que necesaria.

Frédéric Siordet, entonces vicepresidente, fue también el portavoz de la delegación del CICR en la XVIII Conferencia Internacional de la Cruz Roja en Toronto de 1952, en plena guerra de Corea, en la que las delegaciones gubernamentales y de las Sociedades Nacionales de los países marxistas, especialmente, atacaron con virulencia al CICR, arguyendo, resumido muy crudamente, que sólo era «un instrumento del imperialismo capitalista». La valerosa, lúcida y objetiva defensa del CICR que Frédéric Siordet hizo ante la Asamblea plenaria de la Conferencia quedará para siempre como un monumento del más puro espíritu de Cruz Roja.

Otro rasgo conmovedor del hombre de acción que fue Frédéric Siordet: cuando Georges Olivet, joven y prometedor delegado del CICR fue muerto, en 1962, en Katanga (Zaire), en circunstancias particularmente trágicas y delicadas, Frédéric Siordet, entonces miembro del Comité, se ofreció como voluntario para repatriar los restos mortales.

Frédéric Siordet era también deportista y fue uno de los principales animadores del club de bolos del CICR. El autor de estas líneas tuvo el agrado de disfrutar asimismo con él numerosas partidas de tenis o de billar.

Así nos ha dejado un gran servidor de la humanidad, cuya sinceridad, honrades y transparencia, realzada por su aguda inteligencia conquistaron a muchos escépticos, o incluso adversarios, para la causa de la Cruz Roja, y que inspiró a toda una generación de hombres más jóvenes a proseguir por esa vía.

Melchior Borsinger 